\title{
PROPOSTA DE MELHORIAS NOS CURSOS DE GRADUAÇÃO EM ENGENHARIA POR MEIO DE UMA APLICAÇÃO DE UM FRAMEWORK DE GESTÃO DO CONHECIMENTO
}

\author{
DOI: 10.37702/2175-957X.COBENGE.2021.3692
}

Jose Belo Torres - belo@ufc.br universidade federal do ceara antonio baima 224

61940-075 - maranguape - CE

Resumo: Os professores dos cursos de engenharia, basicamente, ensinam como os seus antigos professores. Normalmente, têm poucos conhecimentos pedagógicos e uma formação inadequada na área para suprir suas deficiências. $O$ princípio de uma mudança no Processo de Ensino-Aprendizagem parte da crença em que é o aluno e não o professor o protagonista desse processo. Essa consciência é de fundamental importância para os professores buscarem novas formas de conduzir suas disciplinas. Diante desse contexto complexo, observa-se a inovação e a criatividade como fatores de melhorias nos cursos de engenharia. $O$ mundo vive a era do conhecimento e a gestão do conhecimento é uma área importante na inovação e na criatividade das organizações por meio de seus modelos. Esses modelos de gestão do conhecimento são uma representação simplificada da realidade, mas, podem ser mais abrangentes com a incorporação de um framework. Este framework é constituído do modelo genérico de GC adaptado, do ba, das questões, conceitos e ações sobre o objeto de estudo, do produto/processo desenvolvido, dos ativos de conhecimentos e da sistemática do uso desses elementos. Portanto, este trabalho tem como objetivo geral aplicar um framework de gestão do conhecimento com o intuito de obter melhorias nos cursos de graduação de engenharia. Um dos resultados obtidos foi à criação de uma linha de pesquisa para os cursos de pós-graduação chamada de Engenharia na Educação, se somando ao termo Educação na Engenharia.

Palavras-chave: Ensino-aprendizagem. Framework. Gestão do conhecimento. Modelo SECI 


\section{PROPOSTA DE MELHORIAS NOS CURSOS DE GRADUAÇÃO EM ENGENHARIA POR MEIO DE UMA APLICAÇÃO DE UM FRAMEWORK DE GESTÃO DO CONHECIMENTO}

\section{INTRODUÇÃO}

Os professores dos cursos de engenharia, basicamente, ensinam como os seus antigos professores. Normalmente, não têm os conhecimentos pedagógicos e não procuram uma formação para suprir suas deficiências nessa área. Segundo Behrens (2007), as instituições educacionais procuram ofertar cursos e palestras estanques para formação de professores e que estes momentos isolados não resolvem esta problemática e afirma, ainda, os cursos de mestrado e doutorado em educação, em função das vagas limitadas, acolhem poucos docentes que procuram uma qualificação pedagógica para exercer a docência.

O princípio de uma mudança cultural no Processo de Ensino-Aprendizagem - PEA parte da crença em que é o aluno e não o professor o protagonista desse processo. Essa consciência é de fundamental importância para os professores buscarem novas formas de conduzir suas disciplinas. Diante desse contexto complexo, observa-se a inovação e a criatividade como fatores de melhorias nos cursos de engenharia. Segundo Crossan e Apadyn (2010), a inovação pode ser definida como um processo e um resultado e, ainda, que o processo irá sempre preceder a inovação como um resultado. Torres e Varvakis (2020) afirmam que o conhecimento é o elemento seminal da inovação justificando, assim, o uso da Gestão do Conhecimento - GC como uma área responsável pela inovação e criatividade. Para isso, existem os modelos de GC como os de Nonaka e Taheuchi (2008) e Torres et al. (2017).

Torres e Varvakis (2020), a partir de um modelo genérico de GC, propuseram o framework aplicado nesse trabalho. O conceito de framework, segundo Gerges (2020), é uma estrutura que organiza e une aspectos que dão coerência para diversos símbolos e elementos e incluem eventos ou aspectos que são relevantes para compreensão de uma situação. Modelo genérico de GC é definido como um modelo que pode ser aplicado em vários objetos de estudo e a GC é definida como um conjunto de processos de planejamento, aquisição, criação, armazenamento, compartilhamento e disseminação do conhecimento voltado para inovação. Para isso, o framework propõe, além do modelo genérico, um conjunto de outros elementos relacionados ao seu objeto de estudo, o ensinoaprendizagem.

Em função disso, este trabalho tem como objetivo geral aplicar o framework de GC com o intuito de obter melhorias nos cursos de graduação de engenharia e um dos resultados obtidos foi à criação de uma linha de pesquisa para os cursos de pós-graduação chamada de Engenharia na Educação e Educação na Engenharia. O restante desse trabalho está organizado da seguinte forma. Na seção dois, apresenta-se o referencial teórico abordando o ensino-aprendizagem e a GC. O framework de GC é apresentado na seção três e na seção quatro é apresentada a aplicação do framework. A conclusão é apresentada na seção cinco. 


\section{REFERENCIAL TEÓRICO}

As subseções seguintes apresentam a fundamentação teórica para a aplicação do framework proposto para o objeto de estudo ensino-aprendizagem.

\subsection{O ensino da engenharia}

O ensino-aprendizagem é constituída de uma ampla área de estudo. Os seguintes exemplos podem ser citados: as metodologias ativas e baseadas em competências, as abordagens pedagógicas, os Objetos de Aprendizagem - OAs, o Design Instrucional - DI, a aprendizagem significativa, os mapas conceituais, as ferramentas de autoria e a taxonomia de Bloom. Os professores de engenharia, entretanto, para ter uma boa formação pedagógica, necessitam, primeiramente, ter a crença nos "novos" paradigmas em que o aluno é o protagonista do ensino-aprendizagem para depois buscar adquirir essa formação pedagógica.

Segundo Richartz (2015), as metodologias ativas têm como princípio teórico a autonomia e com elas, o aluno constrói seu conhecimento em vez de recebê-lo de forma passiva do professor. Corroborando com Richartz (2015), Dias e Chaga (2017) afirmam que as metodologias ativas possuem a finalidade de desenvolver o PEA com o foco no desenvolvimento da autonomia do aprendiz. Perrenoud, em uma entrevista a Gentile (2020), afirma que as metodologias por competências é uma maneira de tratar uma problemática antiga, aquela que ensinar é transferir conhecimentos e diz, também, que a descrição de competências deve partir da análise de situações e das ações das práticas sociais nas quais as pessoas são e serão verdadeiramente confrontadas e disso derivar conhecimentos. Ainda em Gentile (2020), Perrenoud afirma, antes de ter competências técnicas, o professor deveria ser capaz de identificar e de valorizar suas próprias competências dentro de sua profissão para ajudar os alunos a desenvolver competências. Uma área com uma relação forte com as metodologias baseadas em competência é a taxonomia de bloom.

A taxonomia de bloom revisada (Pinto, 2015), propõs uma matriz na qual as colunas representam um conjunto de processos cogntivos e as linha representam um conjunto de conhecimentos. A interseção entre as células constituem os objetivos ou competências que devem ser alcancados sobre determinados conteúdos. A interseção entre o processo cognitivo criação e o conhecimento meta-cognição é a mais alta classifcação de competência ou objetivo encontrado na taxonomia de bloom. Para apoiar o desenvolvimento de metodologias baseadas em competências têm-se o DI, os OAs e os softwares de autoria.

O DI propõe estratégias de ensino e de atividades, além dos simples desenvolvimentos de OAs. Filatro (2008) tratou os aspectos de projeto de ensinoaprendizagem por meio de uma abordagem chamada de Design Instrucional Contextualizado e a definiu como a "ação intencional e sistemática de ensino, que envolve o planejamento, o desenvolvimento e a utilização de métodos, técnicas, atividades, materiais, eventos e produtos educacionais em situações didáticas específicas, a fim de facilitar a aprendizagem humana a partir dos princípios de aprendizagem e instrução conhecidos".

Para Braga (2014), os OAs podem ser vistos como unidades digitais, catalogados e disponibilizados em repositórios na Internet para serem reutilizados para o ensino e identifica duas características, a pedagógica e a técnica. As características pedagógicas fazem referências aos trabalhos de professores e alunos, visando à aquisição do 
conhecimento como Interatividade, Autonomia, Cooperação, Cognição e Afetividade, enquanto as técnicas estão relacionadas à Granularidade, a Agregação e a Reusabilidade. São exemplos de OAs as imagens, os áudios, os vídeos, a simulação, os hipertextos, os softwares e as animações. Além disso, Braga (2014) afirma que um OA é mais interativo em função da capacidade de intervenção do aluno no conteúdo ensinado por esse OA, ou seja, quanto mais o OA permite que o aluno se aproprie de informações, reflita e seja ativo em seu processo de aprendizagem, mais interativo ele é. O princípio de todas a fundamentação teórica citadas acima se encontram nas abordagens pedagógicas.

Segundo Reis (2013), o construtivismo é uma abordagem pedagógica que se baseia numa ação tutorial do professor que, ao invés de ensinar, induz o aluno a aprenderaprender através da busca orientada do conhecimento que o aluno necessita. Segundo Fernandes (2011), em outra abordagem chamada cognitivista, o aluno processa a informação, compreende-a e dá-lhe significado, ou seja, entende a aprendizagem como um processo no qual as informações recebidas se relacionam com as informações já existentes no conhecimento do aluno. A citação leva também a definição de aprendizagem significativa. Nesta perspectiva, essas abordagens formam o embasamento teórico para ampla área de estudo do ensino-aprendizagem.

\subsection{A gestão do conhecimento}

Atualmente, vive-se a era do conhecimento. Leite (2006) afirma que o conhecimento é uma estrutura cognitiva dos seres humanos e, portanto, não pode ser gerido, contudo, os processos que exercem algum tipo de controle sobre as condições de criação, compartilhamento e uso desse conhecimento são objetos da GC. Nonaka e Takeuchi (2008) dividem a GC nas dimensões ontológicas e epistemológicas. A dimensão ontológica parte do entendimento que o conhecimento só é criado por indivíduos e se amplia para grupos, organização e interorganização. A dimensão epistemológica tem com fundamento a distinção entre o conhecimento tácito e o explícito. A partir desses tipos de conhecimentos, foi construída a espiral do conhecimento chamada de SECI - Socialização, Externalização, Combinação e Internalização.

O modelo SECl propõe a conversão dos conhecimentos tácitos e explícitos. A Socialização é a conversão do conhecimento tácito em conhecimento tácito. A Externalização é um processo articulado do conhecimento tácito em conceitos explícitos expressos na forma de metáforas, analogias, hipóteses ou modelos sendo a escrita uma forma de conversão. Segundo eles, a Externalização é a chave para a criação do conhecimento, pois cria conceitos novos e explícitos a partir do conhecimento tácito. A combinação é um processo de sistematização de conceitos em um sistema de conhecimentos e esse modo de conversão do conhecimento envolve a combinação de conjuntos diferentes de conhecimento explícito. Por último, tem-se a transformação do conhecimento explícito para o conhecimento tácito e isso está intimamente relacionado ao "aprender fazendo", Internalização. Segundo os autores, para viabilizar a disseminação do conhecimento organizacional, o conhecimento tácito precisa ser socializado com os outros membros da organização, iniciando assim uma nova espiral de criação do conhecimento.

Além do modelo SECI, Nonato e Takeuchi (2008) propuseram um modelo de cinco fases do processo de criação do conhecimento, Figura 1. O Compartilhamento do Conhecimento Tácito relaciona-se com a Socialização, enquanto a Criação de Conceitos corresponde a Externalização. A Justificativa de Conceitos corresponde à validação do conceito criado, enquanto a Construção de um Arquétipo ocorre quando o conceito justificado é transformado em algo tangível ou concreto, "podendo ser considerado um protótipo no caso do desenvolvimento de um novo produto", Combinação. A Difusão 
Interativa do Conhecimento corresponde à transformação do conhecimento criado para um nível ontológico diferente na organização, Internalização.

Figura 1 - O Modelo de Cinco Fases do Processo de Criação do Conhecimento

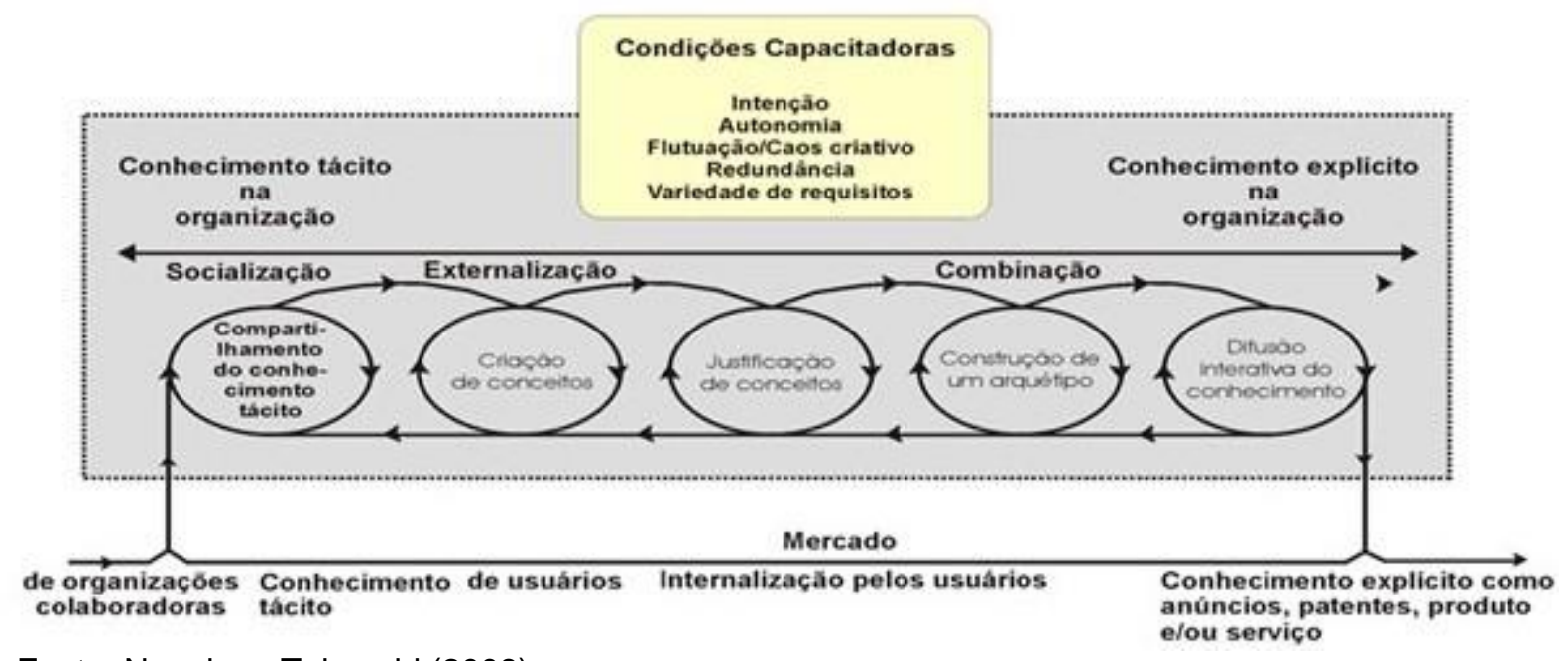

Fonte: Nonaka e Takeuchi (2008)

Para os modelos de GC, foi proposta uma estrutura de apoio as transformações dos conhecimentos chamada de contexto capacitante - ba. Segundo Nonaka e Takeuchi (2008), esta estrutura foi originalmente proposta por Nishida que significa não apenas um espaço físico, mas um tempo e um espaço específicos como um espaço de escritório, um espaço virtual e um espaço mental com ideias compartilhadas. Eles definiram quatro tipos de ba com duas dimensões de interações. A primeira dimensão é o tipo de interação, ou seja, se a interação ocorre individualmente ou coletivamente e a segunda dimensão é a mídia utilizada em tais interações como contato face a face ou mídia virtual. O originating ba é um lugar onde os indivíduos compartilham experiências, sentimentos, emoções e modelos mentais e oferece principalmente um contexto para a socialização de conhecimentos. $\mathrm{O}$ dialoguing ba é definido por interações coletivas e face a face. É o lugar onde os modelos e habilidades mentais individuais são compartilhados, convertidos em termos comuns e articulados como conceitos, externalização. O systemising ba é definido por interações coletivas e virtuais e oferece, principalmente, um contexto para a combinação de conhecimento explícito existente. O exercising ba é definido por interações individuais e virtuais, contexto de internalização, na qual os indivíduos incorporam conhecimento explícito por meio de mídias virtuais como manuais escritos.

\section{O FRAMEWORK PROPOSTO}

O framework proposto (Torres e Varvakis, 2020) tem como objetivo apoiar de forma mais efetiva os processos de criação, de compartilhamento e de disseminação de conhecimento. O framework acrescenta alguns elementos ao modelo genérico de GC proposto por Torres et al. (2017) prescrevendo como e quando cada elemento é utilizado de forma sistemática. O framework, Figura 2, é constituído do modelo genérico de GC adaptado, do ba, das questões, conceitos e ações sobre o objeto de estudo, do produto/processo desenvolvido, dos ativos de conhecimentos e da sistemática do uso desses elementos. 
Figura 2 - O Framework da Gestão do Conhecimento

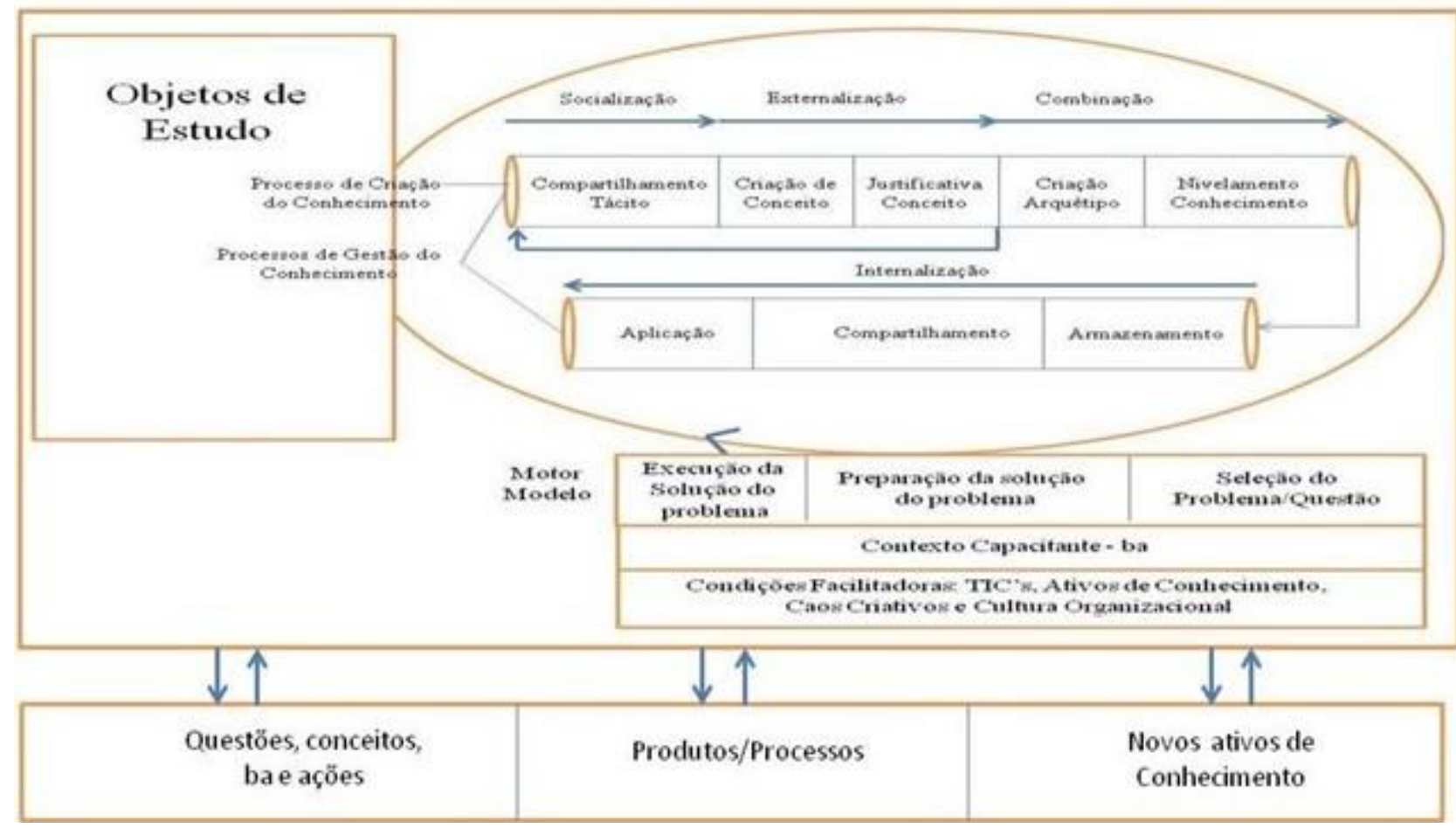

Fonte: $\mathrm{O}$ autor

\subsection{O modelo genérico de GC adaptado}

O modelo genérico adaptado de Torres et al. (2017) utilizou como fundamentos o modelo de cinco fases de criação do conhecimento e o modelo SECI (Nonaka e Takeuchi, 2008), os contextos capacitantes - ba (Alvarenga Neto e Choo, 2011), os ativos do conhecimento e a comunidades de práticas (Dalkir, 2011). A adaptação foi realizada em função de um conjunto de questões, conceitos, ações e contexto capacitante - ba elaborados preliminarmente. O modelo genérico adaptado seleciona uma questão original do portfólio de questões em vez de criar uma questão como era feito no modelo anterior. Essa adaptação provoca uma mudança em relação ao início do processo de Criação do Conhecimento. O processo inicia agora com a fase Justificativa do Conceito em vez do Compartilhamento do Conhecimento Tácito. Além disso, o modelo genérico adaptado propôs uma iteração entre as fases Compartilhamento de Conhecimentos Tácitos (Socialização), Criação do Conceito (Externalização) e Justificativa do Conceito. Essa iteração será apresentada na sistemática do modelo.

\subsection{O contexto capacitante - ba}

O contexto capacitante - ba propicia uma estrutura, principalmente, de pessoas e tecnologias capazes de facilitar os processos e ações de apoio a GC. Assim as organizações podem ter uma estrutura ampla capaz de dar suporte aos quatro tipos de ba's. Assim, o contexto capacitante ba proposto foi dividido em Pessoas e Tecnologias, sendo as mídias de comunicação responsável pela interação entre as pessoas, se face a face ou por meio virtual por intermédio das Tecnologias de Informação e comunicação. Foram propostas, então, as estruturas para os quatro tipos de contextos capacitantes ba's divididos em Tecnologias, T e Pessoas, P. Como exemplo, é apresentado a estrutura 
do originating ba, TO, para as tecnologias: Um ambiente colaborativo com videoconferência, chat, fóruns e comunidades de práticas. Para as pessoas, PS: Encontros presenciais de participantes com conhecimentos pedagógicos e de engenharia para discussão sobre temas com pautas e planos bem definidos.

\subsection{As questões, conceitos e ações originais}

Nessa seção, são apresentadas as questões, os conceitos e as ações originais identificadas para os problemas do PEA. As questões, conceitos e ações originais foram divididas em três grupos. O primeiro grupo, constituído de questões genéricas, identifica os ativos de conhecimentos e, consequentemente, o nível de maturidade encontrado nos cursos em relação às práticas e conhecimentos no ensino-aprendizagem. Para essas questões, serão elaborados conceitos e ações que pretendem elevar o nível de maturidades da instituição, se implementadas. O segundo grupo é constituído de questões referentes sobre o principal documento de orientação de melhoria dos cursos, as DCNs dos cursos de engenharias. Questões sobre a pesquisa científica fazem parte do terceiro grupo. O quadro 1 apresenta uma questão, dois conceitos e uma ação do total de sete questões, nove conceitos e quatorze ações criadas para o grupo de questões genéricas originais. As implementações das ações originais são elaboradas gerando novas questões, conceito e ações chamadas de derivadas. É importante frisar que as questões originais foram elaboradas utilizando as duas primeiras fases do processo de criação do conhecimento, 0 Compartilhamento do Conhecimento Tácito e a Criação do Conceito.

Quadro 1 - Questões, conceitos e ações genéricas originais

\begin{tabular}{l} 
Q1O. O grupo de professores conhece e/ou está familiarizado com alguns recursos utilizados no PEA como \\
OA, DI, abordagens pedagógicas, metodologias ativas, aprendizagem significativa, software de autoria, \\
desenvolvimento cognitivo e taxonomia de Bloom? \\
\hline C1O. Ter produtos/serviços que mude a cultura organizacional em relação ao PEA. \\
\hline C2O. Ter uma perspectiva de Engenharia na Educação em que artefato/produtos possam ser propostos e \\
desenvolvidos. \\
\hline $\begin{array}{l}\text { A1O. Elaborar um projeto para uma linha de pesquisa nos cursos de pós-graduação stricto-sensu chamada } \\
\text { de Engenharia na Educação e Educação na Engenharia para formação de professores-pesquisadores nas } \\
\text { áreas de engenharias e afins integrando os conteúdos pedagógicos com os de engenharia, principalmente, } \\
\text { em relação à inovação e a criatividade no desenvolvimento de Produtos de Aprendizagem de Engenharia } \\
\text { chamados de PAE's. }\end{array}$ \\
\hline chom
\end{tabular}

A2O. Elaborar um projeto de formação de professores.

Fonte: 0 autor

\subsection{Os produtos/processos e ativos de conhecimentos}

Nesse trabalho, os produtos/processos e os novos ativos de conhecimentos são provenientes da solução de um problema de uma ação proposta. As soluções são depois armazenadas, compartilhadas e disseminadas por meio de um sistema de informação.

\subsection{A sistemática de funcionamento do framework}

A sistemática de funcionamento do framework inicia-se, sempre, com o disparo do motor com a seleção de uma ação original. Em seguida, a organização da solução do problema é elaborada com os ajustes no ba. A terceira etapa, execução da solução do problema está relacionado com o processo de criação do conhecimento e inicia-se na fase Justificativa do Conceito. Ao término da fase Justificativa do Conceito, o fluxo pode ter dois destinos, retornar para o Compartilhamento de Conhecimentos Tácitos ou seguir para a Criação do Arquétipo. A decisão se dá em função de três condições. Primeira, os conceitos 
analisados são considerados inadequados? Se verdadeira, volta-se para definição de novos conceitos e ações. Segunda, falta à definição de alguma questão e, consequentemente, os conceitos e ações para a ação analisada? Se verdadeira, uma nova questão, conceitos e ações devem ser identificadas. Esse tipo de questão é chamado de nível 1, caso seja dependente da ação original, nível 2, caso seja dependente do nível 1 e, assim, sucessivamente. Na terceira, a ação analisada não tem um nível de detalhamento suficiente para ser elaborada? Se verdadeira, uma nova questão é elaborada com seus conceitos e ações para a ação analisada. Nessa situação, a questão abordada faz parte do nível 2 em diante. Essa condição acontece quando todas as questões dependentes da ação de nível anterior tenham sido definidas. A iteração continuará a ocorrer, se pelo menos uma condição for verdadeira, caso contrário, o processo segue para a fase de Criação do Arquétipo para a elaboração de todas as ações. Após a Criação do Arquétipo, as fases seguintes do modelo genérico adaptado de GC são executadas.

\section{UMA APLICAÇÂO DO FRAMEWORK NO ENSINO-APRENDIZAGEM}

A aplicação do framework iniciou com o disparo do motor. A primeira ação original A10 do quadro 1 foi selecionada. Os ba's foram revistos e a sua estrutura não foi modificada. Em seguida, a execução do processo foi iniciada com a fase Justificativas dos Conceitos. A primeira condição analisada mostrou os conceitos $\mathrm{C} 1 \mathrm{O}$ e $\mathrm{C} 2 \mathrm{O}$ adequados para a questão A1O e, assim, a condição seguinte foi iniciada. A segunda condição testada, então, identificou a ausência de questão e o processo retornou para as fases Compartilhamento de Conhecimento Tácito e Criação do Conceito para que uma nova questão fosse elaborada. Essa iteração continuou a ocorrer até terminar com o conjunto de questões, conceitos e ações. O quadro 2 apresenta um exemplo dessa construção para duas questões do total de oito questões, vinte e dois conceitos e oito ações.

Quadro 2 - Questões, conceitos e ações derivadas do PEA para a ação A1O

Q1D. Quais as justificativas para a criação de uma linha de pesquisa proposta para os cursos de pósgraduação Stricto-Sensu nas engenharias?

C1D. Ter a formação de professores-pesquisadores de engenharia e áreas afins competentes para atuação na educação e na engenharia por meio da inovação e da criatividade no desenvolvimento de novos artefatos/Produtos de Aprendizagem de Engenharia, PAEs.

C2D. Ter uma definição e uma descrição do PAE, seus tipos e classificação.

C3D. Ter PAE que tenha como princípio apresentar a sua funcionalidade e seus conhecimentos embutidos de forma autônoma e interativa para realização das suas funcionalidades.

C4D. Ter a garantia da utilidade do PAE para o uso no ensino de engenharia e áreas afins.

C5D. Ter resultados de melhorias no ensino de engenharia e áreas afins com o projeto de uma linha de pesquisa de um curso de pós-graduação Stricto-Sensu nos cursos de engenharias.

A1D. Elaborar um texto fundamentado sobre a importância de formação de professores-pesquisadores inovadores e criativos com conhecimentos em pedagogia e em engenharia com o objetivo de desenvolver modelos e métodos sobre o ensino-aprendizagem de engenharia e PAE's.

Q2D. Qual o objetivo de uma linha de pesquisa para os cursos de pós-graduação Stricto-Sensu nas engenharias?

C1D. Ter professores competentes no ensino-aprendizagem de engenharias e áreas afins e na sua área de atuação de engenharia.

A1D. Elaborar um texto sobre uma linha de pesquisa para os cursos de pós-graduação Stricto-Sensu em que a formação de professores-pesquisadores para o ensino de engenharia e a atuação na sua pesquisa na área de engenharia são os principais objetivos.

Fonte: o autor

$\mathrm{Na}$ terceira condição, foram observados que todos os conceitos apresentados se mostraram adequados para suas ações e estas se encontravam completas e prontas para serem elaboradas, portanto, não precisavam mais ser desdobradas em novas questões, 
seguindo assim para a fase Criação do Arquétipo. As subseções seguintes apresentam a descrição das principais ações derivadas da ação original A1O para a linha de pesquisa de um curso de pós-graduação e que a maioria não foi apresentada no quadro 2.

\subsection{A justificativa de uma linha de pesquisa para um curso de pós-graduação}

A formação pedagógica do professor é fundamental para sua profissão. Para campos (2018), os professores foram formados numa lógica em que se tem a ação pedagógica centrada no ensino e o modelo de aulas exagera no instrucionismo e no uso de pedagogias tradicionais e que as experiências verdadeiras construtivistas são raras. Ele termina sobre essa problemática afirmando que é necessário um investimento correto na formação continuada dos professores para fazer uma nova escola possível. Essas problemáticas levantam a importância das abordagens construtivistas (Franco, 1995) e sócioconstrutivistas (Fonseca, 2018) como base de uma formação pedagógica dos professores. Para Yanez (2013), existem dois aspectos importantes em relação ao ensinoaprendizagem, a atualização de conhecimentos pelos professores e o aumento da autonomia dos alunos e que a atualização de docentes nas novas demandas de ensino, centradas nos alunos, é um grande desafio que surge em resposta a um alunado radicalmente diferente dos alunos ao que era habitual. Kuller e Rodrigo (2013) citam que a maioria dos professores acredita que a parte técnica é mais importante que a parte pedagógica no ensino-aprendizagem de engenharia.

Assim, os resultados de uma política de ofertar cursos e palestras estanques são muitas vezes insatisfatórios, pois, os professores precisam, antes disso, crer que o protagonista do ensino-aprendizagem é do aluno e não do professor. Perrenoud (1999) faz uma crítica às universidades por não ter nos seus objetivos uma formação baseada em competências e afirma mesmo quando a preocupação é com a "formação da mente", prevalece à ideia de que basta um comércio intensivo e crítico dos conhecimentos. Portanto, para que uma mudança cultural ocorra no PEA, às ações devem partir de todos os professores dos cursos e, para isso, é fundamental um projeto de formação de futuros professores, em que a crença nas abordagens tradicionais não exista mais. Normalmente, além da falta de conhecimentos dos conteúdos pedagógicos dos professores, falta também conhecimentos de áreas responsáveis pela inovação e criatividade.

Para isso, este texto propõe uma linha de pesquisa para os cursos de pós-graduação de engenharia chamada de Engenharia na Educação e Educação na Engenharia. A linha de pesquisa poderia, por exemplo, ser adotada por todos os cursos de pós-graduação em um centro de tecnologia e ser coordenado por um grupo de professores. Esse modelo seria imediato e dependente, principalmente, somente do convencimento dos cursos de pósgraduação. A coordenação da linha de pesquisa poderia, também, ser coordenada por seu próprio curso. Assim, as mudanças culturais e crenças podem se concretizar por meio de propostas inovadoras e criativas no médio e longos prazo com a formação de novos professores nessa linha de pesquisa de um curso de pós-graduação. Assim, os professores-pesquisadores com formação em engenharia e áreas afins podem atuar no PEA e ao mesmo tempo podem se engajar em projetos de engenharias de seus interesses. Essa proposta foi dividida em duas áreas de pesquisas. A primeira trata de propostas de desenvolvimento de modelos e métodos educacionais e de desenvolvimento dos PAE's, enquanto a segunda trata de pesquisas tradicionais da educação na engenharia.

Quanto aos modelos e métodos são propostas educacionais aplicadas no ensinoaprendizagem das engenharias e para o desenvolvimento dos PAE's. Em relação ao PAE, pode ser definido como um objeto/produto capaz de forma autônoma, apresentar de forma integrada os seus conhecimentos e as suas funcionalidades embutidas. Portanto, deve 
apresentar aos aprendizes de forma autônoma e interativa os conhecimentos, as funcionalidades, conceitos e conteúdos contidos nele. Um PAE pode ser dividido em dois tipos, real e virtual. O tipo real pode ser descrito como um artefato/produto com suas funcionalidades, enquanto o virtual pode ser descrito como um Objeto de Aprendizagem acrescentando a ele as suas funcionalidades. Ambos devem apresentar as tecnologias e conhecimentos embutidos em seu funcionamento. Um PAE, seja ele real ou virtual, possui as características dos OAs propostas em Braga (2014). Então, entre um PAE virtual e um OA, poder-se-ia dizer que a principal diferença entre eles é o fato de o PAE apresentar um produto que possui de forma integrada os conhecimentos e as funcionalidades embutidos ou contidos nele. Assim, em função dessas semelhanças, o PAE, seja virtual ou real deve guardar as características dos OAs, mas possuir as funcionalidades que não existem nos OAs. Um exemplo de um PAE real pode ser visto por meio de uma máquina de ensaios de tração em um material. Esse ensaio pode estar integrado a um computador apresentando o diagrama tensão-deformação. Além disso, apresentando os OA's com vários conteúdos sobre o tema. Esse exemplo pode, também, ser desenvolvido de forma virtual.

\subsection{Os objetivos}

A linha de pesquisa em Engenharia na Educação e Educação na Engenharia teria como objetivo principal formar professores-pesquisadores com conhecimento na área de educação e de engenharia por meio de desenvolvimento de métodos e modelo e desenvolvimento de PAE's através de áreas responsáveis pela inovação e criatividade como a GC e o Design Thinking com o intuito de apoiar o ensino-aprendizagem de engenharia e áreas afins. Assim, o professor-pesquisador teria uma formação pedagógica sem se afastar de sua linha de pesquisa em engenharia. Em síntese, a primeira área da linha de pesquisa proposta tem como objetivo a atuação do professor-pesquisador na construção de ideias inovadoras e criativas para melhorias no ensino-aprendizagem de engenharia e áreas afins no desenvolvimento de modelos e métodos de ensinoaprendizagem e de PAE's.

\subsection{Os Conteúdos}

Esse tema surgiu com a seguinte questão: Quais seriam os principais conteúdo a ser abordados em uma linha de pesquisa de um curso de pós-graduação Stricto-Sensu em Engenharia na Educação e Educação na Engenharia? Desse questionamento, surgiram algumas características ou funções como ter uma disciplina obrigatória focada na área de ensino-aprendizagem. No programa da linha de pesquisa, é fundamental tratar as abordagens pedagógicas como o construtivismo e o sócio construtivismo, tema base do ensino-aprendizagem. A criatividade e a inovação são conteúdos importantes e pode ser abordado de forma transversal. As outras disciplinas são de conteúdos tecnológicos da própria atuação do professor-pesquisador. Enfim, seria importante o professor-pesquisador ter conhecimentos, além de sua área de atuação, ter conhecimentos sobre o ensinoaprendizagem como as abordagens pedagógicas, DI, OA e a taxonomia de bloom, por exemplo.

\subsection{Os resultados esperados}

Os resultados das pesquisas elaborados por seus alunos-pesquisadores são modelos, métodos e ferramentas educacionais para o desenvolvimento de PAE's baseados na inovação e na criatividade. As pesquisas devem produzir, também, PAE's em que os 
seus conhecimentos e funcionalidades embutidos neles possam ser "visualizados" ou apresentados de uma forma autônoma, prática e interativa para apoiar o ensinoaprendizagem nas áreas de engenharia e afins. Além disso, resultados diversos sobre aplicação na Educação na Engenharia, uma área já tradicional no ensino-aprendizagem.

\section{CONCLUSÃO}

De forma específica, o framework a partir do modelo genérico adaptado, da sistemática apresentada, das questões, dos conceitos, das ações e dos ba's previamente elaborados atendeu ao objetivo geral desse trabalho por meio de uma proposta de melhorias dos cursos de engenharia. Para isso, foi inicialmente selecionada uma ação original do framework depois do disparo do motor. O trabalho apresentou, ainda, a importância da GC como uma área responsável por temas como a inovação e a criatividade por meio do uso do modelo SECl e do modelo de cinco de fases de criação do conhecimento proposto no framework com sua sistemática. Nesta, das três condições propostas, as duas primeiras foram utilizadas, no entanto, um exemplo da utilização da terceira condição pode ser vista em Torres e Varvakis (2020).

Quanto ao resultado de melhorias nos cursos de graduação de engenharias por meio do framework de GC, foi proposta uma linha de pesquisa chamada de Engenharia na Educação e Educação na Engenharia. A proposta pode-se afirmar positiva em função da existência de poucos cursos de mestrado e doutorado na área pedagógica e a difícil mudança cultural nos cursos de engenharias existentes. Um ponto fundamental nesta proposta, para a primeira área da linha de pesquisa, é a atuação do pesquisador-professor tanto na pesquisa de ensino-aprendizagem quanto na área de engenharia. Outro ponto importante é a proposta dos PAE's no apoio ao aluno de graduação por meio dos conhecimentos e funcionalidades embutidos neles e com as características advindas dos OA's. A segunda área da linha de pesquisa torna a proposta ampla para melhorias no ensino-aprendizagem. Para futuros trabalhos, serão desenvolvidas outras ações definidas para o grupo de ações genéricas, para o grupo das DCN's e para o grupo da pesquisa cientifica originais do framework proposto.

\section{REFERÊNCIAS}

ALVARENGA NETO, Rivadávia Correa Drummond de; CHUN, Wei Choo. Expanding the concept of Ba: managing enabling contexts in knowledge organizations. Perspectivas em Ciência da Informação, v.16, n.3, p.2-25, jul./set. 2011.

BEHRENS, Marilda Aparecida. O Paradigma da complexidade na formação e no desenvolvimento profissional de professores universitários. Educação. Porto Alegre/RS, ano XXX, n. 3 (63), p. 439-455, set./dez. 2007.

BRAGA, Juliana et al. Objetos de aprendizagem. Volume 1 - Introdução e fundamentos. Santo André, SP. Editora da UFABC. Coleção INTERA, 2014.

CAMPOS, Casemiro de Medeiros. Didática: Ferramenta para o trabalho docente em sala de aula. $2^{\text {a }}$ Ed. Fortaleza: Editora Caminhar, 2018.

CROSSAN, M. M.; e APADYN, M. A Multi-Dimensional Framework of Organizational Innovation: A Systematic Review of the Literature. Journal of Management Studies 47:6. P. 1154-1191, September 2010. 
DALKIR, K. Knowledge management in theory and practice. London: The MIT Press, 2011.

DIAS, S. R.; CHAGA, M. M. Aprendizagem baseada em problema: um relato de experiência. In: Dias, Simone Regina; Volpato, Arceloni Neusa (Org.). Práticas inovadoras em metodologias ativas. Florianópolis: Contexto Digital. p. 36-48, 2017.

FILATRO, A. C. Learning Design como Fundamentação Teórico-Prática para o Design Instrucional Contextualizado. Tese (Doutorado) - Programa de Pós-Graduação em Educação. Universidade de São Paulo - USP, Faculdade de Educação. São Paulo, 2008. Disponível em: ttps://www.teses.usp.br/teses/disponiveis/48/48134/tde-12062008142556/pt-br.php. Acessado em 13 Set. 2017.

FONSECA, Vitor Da. Desenvolvimento cognitivo e processo de ensino-aprendizagem: Abordagem psicopedagógica à luz de Vygotsky. Petrópolis RJ: Vozes, 2018.

FRANCO, Sérgio Roberto Kieling. O construtivismo e a educação. 4a ampliada), Porto Alegre, Mediação, 1995.

KÜLLER, J. A.; RODRIGO, N. F. Metodologia de desenvolvimento de competências. Rio de Janeiro: Senac Nacional, 2013.

LEITE, F. C. L. Gestão do Conhecimento Científico no Contexto Acadêmico. Proposta de um Modelo Conceitual. Dissertação (mestrado) - Programa de Pós-Graduação em Ciência da Informação (PPGCInf). Universidade de Brasília (UnB). Disponível em: https://repositorio.unb.br/handle/10482/3975?mode=full. Acessado em 08 Out. 2006.

NONAKA, I.; TAKEUCHI, H. Gestão do conhecimento. Porto Alegre: Editora Bookman. 2008.

PERRENOUD, Philipe. Construir competências desde a escola. Porto Alegre: Editora Artmed, 1999.

GENTILE, Paola; BENCINI, Roberta. Entrevista com Philippe Perrenoud, universidade de Genebra. Disponível em: https://www.unige.ch/fapse/SSE/teachers/perrenoud/php main/php 2000/2000 31.html. Acesso em 02 de Set. de 2020.

PINTO, R. A. Métodos de Ensino e Aprendizagem sob a Perspectiva da Taxonomia de Bloom. CONTEXTO \& EDUCAÇÃO. Editora Unijuí, Ano 30, no 96, pg. 126-155, Maio/Ago. 2015.

REIS, V. W. Avaliação das Influências dos Recursos Didáticos e Métodos de Ensino no Desempenho de Graduação: Um Estudo de Caso no CEFET/RJ. Dissertação (mestrado) - Programa de Pós-Graduação em Tecnologia, Centro Federal de Educação Tecnológica Celso Suckow da Fonseca. CEFET/RJ. Rio de Janeiro, 2013. Disponível em: pppro.cefet-rj.br/T/346_VivianWildhagen Reis.pdf. Acessado em 05 de Jan. 2021. 
RICHARTZ, T. Metodologia ativa: a importância da pesquisa na formação de professores. Revista da Universidade Vale do Rio Verde, Três Corações, v. 13, n. 1, p. 296-304, 2015.

TORRES J. B et al. Um Modelo de Gestão de Conhecimentos no Apoio ao Ensino de Engenharia. VII Congresso Internacional de Conhecimento e Inovação, Foz do Iguaçu/PR, setembro de 2017.

TORRES, J. B.; VARVAKIS, G. J. Proposta de um Framework a Partir de um Modelo Genérico de Gestão do Conhecimento Para a Área de Ensino de um Centro de Tecnologia de uma Instituição de Ensino Federal. X Congresso Internacional de Conhecimento e Inovação, Ciudad Del Saber, Panamá, 19 e 20 de Novembro de 2020.

YAÑEZ, C. S. Propuesta para implementar un sistema de gestión del conocimiento que apoye el diseño de un curso online. Revista chilena de Ingeniería, vol. 21 № 3, 2013, pp. 457-471.

\title{
PROPOSALS FOR IMPROVEMENTS IN ENGINEERING GRADUATION COURSES THROUGH AN APPLICATION OF A KNOWLEDGE MANAGEMENT FRAMEWORK
}

\begin{abstract}
Engineering professors basically teach like their former teachers. They usually have little pedagogical knowledge and inadequate training in the area to make up for their deficiencies. The principle of a change in the Teaching-Learning Process starts from the belief that it is the student and not the teacher who is the protagonist of this process. This awareness is of fundamental importance for teachers to seek new ways of conducting their subjects. In view of this complex context, innovation and creativity are seen as factors for improvement in engineering courses. The world is living in the era of knowledge and knowledge management is an important area in the innovation and creativity of organizations through its models. These knowledge management models are a simplified representation of reality, but they can be more comprehensive with the incorporation of a framework. This framework must consist of a set of questions, concepts and support actions in the solution of the problem-situation. Therefore, this work has the general objective of applying a knowledge management framework in order to obtain improvements in engineering undergraduate courses. One of the results obtained was the creation of a line of research for postgraduate courses called Engineering in Education, adding to the term Education in Engineering.
\end{abstract}

Keywords: Teaching-learning. Framework. Knowledge management. SECI model. 